\title{
Cost-effectiveness of dipeptidyl peptidase-4 inhibitor monotherapy in elderly type 2 diabetes patients in Thailand
}

This article was published in the following Dove Press journal:

ClinicoEconomics and Outcomes Research

21 September 2016

Number of times this article has been viewed

\author{
Unchalee Permsuwan' \\ Piyameth Dilokthornsakul ${ }^{2}$ \\ Surasak Saokaew ${ }^{2-4}$ \\ Kednapa Thavorn ${ }^{5-7}$ \\ Nathorn \\ Chaiyakunapruk $2,4,8,9$ \\ 'Faculty of Pharmacy Chiang Mai \\ University, Chiang Mai, ${ }^{2}$ Center of \\ Pharmaceutical Outcomes Research, \\ Faculty of Pharmaceutical Sciences, \\ Naresuan University, Phitsanulok, \\ ${ }^{3}$ Center of Health Outcomes \\ Research and Therapeutic Safety, \\ School of Pharmaceutical Sciences, \\ University of Phayao, Phayao, Thailand; \\ ${ }^{4}$ School of Pharmacy, Monash \\ University Malaysia, Sunway, Malaysia; \\ ${ }^{5}$ Ottawa Hospital Research Institute, \\ The Ottawa Hospital, ${ }^{6}$ School of \\ Epidemiology, Public Health and \\ Preventive Medicine, Faculty of \\ Medicine, University of Ottawa, \\ Ottawa, ${ }^{7}$ Institute for Clinical and \\ Evaluative Sciences, Toronto, ON \\ Canada; ${ }^{8}$ School of Population Health, \\ The University of Queensland, \\ Brisbane, QLD, Australia; ${ }^{9}$ School of \\ Pharmacy, University of Wisconsin- \\ Madison, Madison, WI, USA
}

Correspondence: Unchalee Permsuwan Faculty of Pharmacy, Chiang Mai University Suthep Road, Muang District, Chiang Mai 50200, Thailand

Tel +66 896359268

Email unchalee.permsuwan@gmail.com
Background: The management of type 2 diabetes mellitus (T2DM) in elderly population poses many challenges. Dipeptidyl peptidase-4 (DPP-4) inhibitors show particular promise due to excellent tolerability profiles, low risk of hypoglycemia, and little effect on body weight. This study evaluated, from the health care system's perspective, the long-term cost-effectiveness of DPP-4 inhibitor monotherapy vs metformin and sulfonylurea (SFU) monotherapy in Thai elderly T2DM patients.

Methods: The clinical efficacy was estimated from a systematic review and meta-analysis. Baseline cohort characteristics and cost parameters were obtained from published studies and hospital databases in Thailand. A validated IMS CORE Diabetes Model version 8.5 was used to project clinical and economic outcomes over a lifetime horizon using a 3\% annual discount rate. Costs were expressed in 2014 Thai Baht (THB) (US dollar value). Incremental cost-effectiveness ratios were calculated. Base-case assumptions were assessed through several sensitivity analyses. Results: For treating elderly T2DM patients, DPP-4 inhibitors were more expensive and less effective, ie, a dominated strategy, than the metformin monotherapy. Compared with SFU, treatment with DPP-4 inhibitors gained 0.031 more quality-adjusted life years (QALYs) at a total cost incurred over THB1 13,701 or US\$3,449.67, resulting in an incremental cost-effectiveness ratio of THB3.63 million or US\$110,133.50 per QALY. At the acceptable Thai ceiling threshold of THB160,000/QALY (US\$4,854.37/QALY), DPP-4 inhibitors were not a cost-effective treatment. Conclusion: DPP-4 inhibitor monotherapy is not a cost-effective treatment for elderly T2DM patients compared with metformin monotherapy and SFU monotherapy, given current resource constraints in Thailand.

Keywords: cost-effectiveness analysis, DPP-4 inhibitor, elderly, type 2 diabetes, Thailand

\section{Introduction}

Type 2 diabetes mellitus (T2DM) is a common chronic health condition in the elderly. The number of elderly T2DM patients has been growing worldwide, especially in uppermiddle income countries such as Thailand. Based on the findings of the Fourth Thai National Health Examination Survey in 2009, diabetes was most prevalent in women, the elderly, and urban areas. The prevalence of impaired fasting glucose and undiagnosed diabetes increased with age, peaking at age $\geq 75$ years and $55-64$ years, respectively. ${ }^{1}$ Diabetes in the elderly is associated with a greater risk of T2DM-related micro- and macrovascular complications, cognitive disorders, physical disability, morbidity, and mortality $;^{2-5}$ the selection of antidiabetic treatment for elderly T2DM patients poses many challenges for a number of reasons. First, elderly T2DM patients have a greater 
incidence of hypoglycemia ${ }^{6}$ which can precipitate serious events such as falls and accompanying fractures. The study by Zhao et $\mathrm{al}^{7}$ showed that hypoglycemia patients had higher rates of fall-related fractures than those without hypoglycemia, within 30 days and 1 year $(0.64 \%$ vs $0.02 \%$ and $2.11 \%$ vs $0.50 \%$, respectively). Second, elderly T2DM patients are more likely to have comorbidities with their diabetes, leading to the use of polypharmacy. ${ }^{4,8,9}$ Third, chronic kidney disease often occurs in elderly T2DM patients; ${ }^{10}$ the prevalence of chronic kidney disease among T2DM patients in Australia, ${ }^{11}$ India, ${ }^{12}$ Finland ${ }^{13}$ Singapore, ${ }^{14}$ and the US ${ }^{15}$ ranged from $40 \%$ to $70 \%$. With these associated challenges for elderly T2DM patients, finding effective and safe therapeutic agents is very crucial.

Dipeptidyl peptidase-4 (DPP-4) inhibitors show particular promise for treating elderly T2DM patients because they have excellent tolerability profiles, low risk of hypoglycemia, and little effect on body weight. ${ }^{4,16,17}$ Therefore, this study evaluated the cost-effectiveness of DPP-4 inhibitor monotherapy compared with sulfonylurea (SFU) monotherapy or metformin monotherapy for treating elderly T2DM patients in the Thai context.

\section{Methods}

\section{Study design and cohort population}

From a Thai health care system perspective, we conducted a cost-utility analysis and used a validated IMS CORE Diabetes Model (CDM), Version 8.5, to estimate long-term costs and outcomes associated with each treatment over a lifetime horizon. Details of this model are described elsewhere. ${ }^{18,19} \mathrm{~A}$ $3 \%$ discount rate per annum was applied to both costs and outcomes in line with the Thai Health Technology Assessment (HTA) guideline. ${ }^{20}$

The cohort population was Thai people with T2DM aged at least 65 years. Table 1 presents the baseline demographics, risk factors, and clinical complications of the cohort, which were obtained from published data and hospital databases in Thailand. ${ }^{21-28}$ The all-cause mortality rate was also adjusted with the age-specific mortality rate of Thai people. ${ }^{29}$ Utility values used in the CDM were based mostly on published studies conducted in other countries. ${ }^{30-34}$

This study was approved by the Buddhachinaraj Regional Hospital Ethics Committee on August 8, 2014. As the patient data is de-identified patient consent was not required.

\section{Interventions in the study}

Our study considered the following DPP-4 inhibitors: saxagliptin, sitagliptin, and vildagliptin. These medications were administered as a monotherapy and then compared with either metformin monotherapy or SFU monotherapy.
Table I Baseline characteristics of the cohort population

\begin{tabular}{|c|c|c|}
\hline Variables & Mean \pm SD & Data sources \\
\hline \multicolumn{3}{|l|}{ Patient demographics } \\
\hline Mean age (years) & $72.8 \pm 5.6$ & BCRH database \\
\hline Duration of diabetes (years) & $10.5 \pm 7.6$ & TDR2006 21 \\
\hline Proportion male & $34.3 \%$ & BCRH database \\
\hline \multicolumn{3}{|l|}{ Risk factors } \\
\hline $\mathrm{HbA}_{\mathrm{Ic}}$ level (\%) & $7.9 \pm 6.6$ & BCRH database \\
\hline Systolic blood pressure $(\mathrm{mmHg})$ & $143.6 \pm 22.4$ & TDR2006 21 \\
\hline Total cholesterol (mg/dL) & $187.4 \pm 45.4$ & BCRH database \\
\hline \multicolumn{2}{|l|}{ cholesterol (mg/dL) } & BCRH database \\
\hline $\begin{array}{l}\text { Low-density lipoprotein } \\
\text { cholesterol }(\mathrm{mg} / \mathrm{dL})\end{array}$ & cholesterol (mg/dL) & BCRH database \\
\hline Triglycerides (mg/dL) & $169.8 \pm 95.6$ & BCRH database \\
\hline Body mass index $\left(\mathrm{kg} / \mathrm{m}^{2}\right)$ & $24.6 \pm 4.1$ & Trongsakul $^{22}$ \\
\hline eGFR $\left(\mathrm{mL} / \mathrm{min} / \mathrm{l} .73 \mathrm{~m}^{2}\right)$ & $66.6 \pm 28.5$ & BCRH database \\
\hline Proportion of smokers & $8.10 \%$ & Trongsakul $^{22}$ \\
\hline $\begin{array}{l}\text { Number of cigarettes smoked } \\
\text { per day }\end{array}$ & 6.0 & $\begin{array}{l}\text { Porapakkham and } \\
\text { Plattara-Archachai }{ }^{23}\end{array}$ \\
\hline Alcohol consumption (mL/wk) & 136.5 & $\begin{array}{l}\text { Center of } \\
\text { Alcohol Studies }^{24}\end{array}$ \\
\hline \multicolumn{3}{|l|}{ Cardiovascular disease complications } \\
\hline Myocardial infarction & $2.4 \%$ & BCRH database \\
\hline Angina pectoris & $1.3 \%$ & BCRH database \\
\hline Peripheral vascular disease & $0.2 \%$ & BCRH database \\
\hline Stroke & $2.5 \%$ & BCRH database \\
\hline Congestive heart failure & $4.7 \%$ & BCRH database \\
\hline Atrial fibrillation & $2.5 \%$ & BCRH database \\
\hline Left ventricular hypertrophy & $0.3 \%$ & BCRH database \\
\hline Cataract & $42.8 \%$ & TDR2006 21 \\
\hline Depression & $19.4 \%$ & $\begin{array}{l}\text { Thaneerat and } \\
\text { Tangwongchai }{ }^{25}\end{array}$ \\
\hline \multicolumn{3}{|l|}{ Foot ulcer complications } \\
\hline Uninfected ulcer & $5.9 \%$ & TDR2003 ${ }^{26}$ \\
\hline Infected ulcer & $1.2 \%$ & Nitiyanant et $\mathrm{a}^{27}$ \\
\hline Healed ulcer & $6.9 \%$ & Nitiyanant et $\mathrm{a}^{27}$ \\
\hline History of amputation & $1.5 \%$ & TDR2006 21 \\
\hline Macular edema & $2.5 \%$ & Supapluksakul et $\mathrm{al}^{28}$ \\
\hline Neuropathy & $2.1 \%$ & BCRH database \\
\hline \multicolumn{3}{|l|}{ Renal complications } \\
\hline Microalbuminuria & $18.0 \%$ & TDR2006²1 \\
\hline Gross proteinuria & $26.1 \%$ & TDR2006 21 \\
\hline End-stage renal disease & $0.1 \%$ & Nitiyanant et $\mathrm{a}^{27}$ \\
\hline \multicolumn{3}{|l|}{ Retinopathy complications } \\
\hline Background retinopathy & $22.0 \%$ & TDR2006 21 \\
\hline Proliferative retinopathy & $9.4 \%$ & TDR2006 21 \\
\hline Severe vision loss & $1.5 \%$ & TDR200621 \\
\hline
\end{tabular}

Abbreviations: BCRH, Buddhachinaraj Regional Hospital; SD, standard deviation; TDR, Thailand diabetes registry.

We used metformin and SFU (glipizide) as comparators for several reasons. First, the Thai HTA guideline ${ }^{35}$ recommends current practice as a comparator. Metformin and SFU are considered as usual care for elderly T2DM patients in Thailand. Second, we convened a panel of stakeholders to discuss the scope and appropriate comparators of the study, including endocrinologists, and policy makers, and then followed the consensus of the meeting. This study used 
the normal daily dose of each treatment option: saxagliptin (5 mg), sitagliptin (100 mg), vildagliptin (100 mg), glipizide $(10 \mathrm{mg})$, and metformin $(2,000 \mathrm{mg})$.

\section{Costs}

Only the direct medical costs, such as cost of intervention, concurrent medications, diabetic screening, management, and treatment complications, were included in the cost-effectiveness analysis. Cost data were derived from the published literature and retrospective hospital database analyses (Table 2). ${ }^{36-41}$ All costs were inflated using Thailand's consumer price index ${ }^{42}$ and presented in the year 2014 THB value. Costs were converted to US\$ at a rate of THB32.96 per US\$ as of December 30, 2014. ${ }^{43}$

The cost of DPP-4 inhibitors was proposed to the subcommittee for the development of the National List of

Table 2 Cost parameters used in the CDM

\begin{tabular}{|c|c|c|c|}
\hline Variables & Mean (THB) & SD & Reference \\
\hline \multicolumn{4}{|l|}{ Management costs } \\
\hline Aspirin & 185 & 119.58 & BCRH database \\
\hline Statin & 2,042 & $4,956.59$ & $\mathrm{BCRH}$ database \\
\hline ACEI & 1,319 & $3,037.85$ & BCRH database \\
\hline Antidepressant & 2,323 & $6,107.65$ & BCRH database \\
\hline Screening for microalbuminuria & 320 & - & Maharaj Nakorn Chiang Mai hospital| ${ }^{36}$ \\
\hline Screening for gross proteinuria & 60 & - & Maharaj Nakorn Chiang Mai hospital ${ }^{36}$ \\
\hline Eye screening & 129 & - & Pornpinatepong ${ }^{37}$ \\
\hline Foot screening program & 70 & - & Standard cost list ${ }^{38}$ \\
\hline \multicolumn{4}{|l|}{ Costs of acute events } \\
\hline Major hypoglycemia & 27,856 & $70,785.76$ & BCRH database \\
\hline Ketoacidosis event & 13,284 & $36,398.48$ & $\mathrm{BCRH}$ database \\
\hline Lactic acidosis event & 64,724 & $97,511.56$ & BCRH database \\
\hline Major hypoglycemia & 27,856 & $70,785.76$ & $\mathrm{BCRH}$ database \\
\hline \multicolumn{4}{|l|}{ Costs of eye diseases } \\
\hline Laser treatment & 1,920 & - & Pornpinatepong ${ }^{37}$ \\
\hline Cataract operation & 7,000 & - & National Health Security Office ${ }^{39}$ \\
\hline Blindness, first year & 30,902 & $|7,675.9|$ & $\mathrm{BCRH}$ database \\
\hline Blindness, subsequent years & 18,766 & $32,900.26$ & BCRH database \\
\hline \multicolumn{4}{|l|}{ Costs of cardiovascular complications } \\
\hline Ml, first year & 106,323 & $129,552.60$ & BCRH database \\
\hline MI, subsequent years & 26,629 & $4 I, 45 I .42$ & BCRH database \\
\hline Angina first year & 60,235 & $83,594.51$ & BCRH database \\
\hline Angina, subsequent years & 19,578 & $28,308.46$ & BCRH database \\
\hline CHF, first year & 58,875 & $79,235.18$ & BCRH database \\
\hline $\mathrm{CHF}$, subsequent years & 25,452 & $39,122.61$ & $\mathrm{BCRH}$ database \\
\hline Stroke, first year & 71,362 & - & BCRH database \\
\hline Stroke, subsequent years & 23,884 & $32,123.49$ & BCRH database \\
\hline Stroke death within 30 days & 38,189 & $4 I, 778$ & BCRH database \\
\hline PVD, first year & 156,394 & $276,600.00$ & BCRH database \\
\hline PVD, subsequent years & 50,374 & $50,253.25$ & BCRH database \\
\hline \multicolumn{4}{|c|}{ Costs of neuropathy and foot complications } \\
\hline Neuropathy, first year & 24,410 & $37,763.1$ & BCRH database \\
\hline Neuropathy, subsequent years & 18,797 & $28,631.95$ & BCRH database \\
\hline Amputation & 48,365 & - & BCRH database \\
\hline Gangrene treatment (yearly) & 76,950 & $95,163.4$ & BCRH database \\
\hline Infected ulcer & 0 & - & Assumption \\
\hline Uninfected ulcer (yearly) & 53,076 & $74,776.36$ & BCRH database \\
\hline \multicolumn{4}{|l|}{ Costs of renal complications } \\
\hline HD, first year & 452,120 & - & Teerawattananon et $\mathrm{al}^{40}$ \\
\hline HD, subsequent years & $428,|4|$ & - & Teerawattananon et al ${ }^{40}$ \\
\hline PD, first year & 460,129 & - & Teerawattananon et al ${ }^{40}$ \\
\hline $\mathrm{PD}$, subsequent years & 408,080 & - & Teerawattananon et $\mathrm{al}^{40}$ \\
\hline RT, first year & 928,000 & - & King Chulalongkorn Memorial Hospital ${ }^{41}$ \\
\hline RT, subsequent years & 429,240 & - & King Chulalongkorn Memorial Hospital ${ }^{41}$ \\
\hline
\end{tabular}

Note: The dash indicates no data available.

Abbreviations: ACEl, angiotensin-converting-enzyme inhibitor; BCRH, Buddhachinaraj Regional Hospital; CDM, IMS CORE Diabetes Model, Version 8.5; CHF, congestive heart failure; HD, hemodialysis; MI, myocardial infarction; PD, peritoneal dialysis; PVD, peripheral vascular disease; RT, renal transplant; SD, standard deviation; THB, Thai Baht. 
Essential Medicine by the pharmaceutical companies. Total cost per year of saxagliptin, sitagliptin, and vildagliptin was THB13,492 (US\$409.34), THB16,570 (US\$502.73), and THB15,900 (US\$482.40), respectively. Glipizide and metformin have several generic products in Thailand. We used a median of the median prices of those generic products ${ }^{44}$ as recommended by the Thai HTA guideline. ${ }^{45}$ The annual total costs of metformin and SFU were THB496 (US\$15.05) and THB149 (US\$4.52), respectively.

\section{Treatment efficacy and adverse events}

Due to limited evidence of treatment efficacy in Thailand, we performed a systematic review and meta-analysis to estimate the pooled efficacy of DPP-4 inhibitor monotherapy compared to SFU monotherapy and metformin monotherapy in elderly T2DM patients. The MEDLINE, EMBASE, and Clinicaltrial.gov databases were systematically searched from their inception to August 2014. We found only one study ${ }^{46}$ that indicated noninferiority of alogliptin compared to glipizide in $\mathrm{HbA}_{1 \mathrm{c}}$ reduction (the weighted mean difference $-0.09 ; 95 \%$ $\mathrm{CI},-\infty$ to 0.06 ), substantially lower risk of hypoglycemia (risk ratio [RR] $0.21 ; 95 \% \mathrm{CI}, 0.11-0.41$ ), lower risk of severe hypoglycemia (RR 0.23; 95\% CI, 0.03-1.99), and no weight gain with DPP-4 inhibitor monotherapy compared to glipizide monotherapy in elderly T2DM patients (Table 3 ).

Three studies ${ }^{5,47,48}$ compared metformin with DPP-4 inhibitor monotherapy and concluded that DPP-4 inhibitor was an effective and well-tolerated treatment option for elderly T2DM patients. In addition, reduction in $\mathrm{HbA}_{1 \mathrm{c}}$ after treatment with DPP-4 inhibitors in elderly T2DM patients was not significantly different from those in younger patients. ${ }^{49}$ Therefore, we decided to systematically search a meta-analysis study that compared DPP-4 inhibitor monotherapy with metformin monotherapy in T2DM patients, and found two eligible studies. ${ }^{50,51}$ Both were high quality studies (with scores of at least 9 of 11) based on the Assessment of Multiple Systematic Reviews, We decided to use Wu et al's ${ }^{51}$ meta-analysis as it was the most up-to-date. The efficacy of $\mathrm{HbA}_{1 \mathrm{c}}$ reduction from the baseline of metformin monotherapy was estimated from the pooled analysis of seven studies $^{48,52-57}$ included in the meta-analysis of Wu et al. ${ }^{51} \mathrm{Of}$ those studies, ${ }^{48,52-57}$ severe hypoglycemia was presented in two

Table 3 Efficacy and adverse effects of DPP-4 inhibitors, metformin, and SFU

\begin{tabular}{|c|c|c|}
\hline Variables & Mean $(95 \% \mathrm{CI})$ & Data sources \\
\hline \multicolumn{3}{|l|}{ Efficacy } \\
\hline \multicolumn{3}{|l|}{$\mathrm{HbA}_{\mathrm{Ic}}$ reduction (\%) } \\
\hline DPP-4 inhibitors vs placebo & $-0.92(-0.8,-1.03)$ & Calculation $^{\mathrm{a}}$ \\
\hline Metformin vs placebo & $-1.20(-0.81,-1.59)$ & Pooled analysis ${ }^{b}$ \\
\hline SFU vs placebo & $-0.83(-0.98,0)$ & Calculation ${ }^{c}$ \\
\hline $\begin{array}{l}\text { Weighted mean difference (\%) (DPP- } 4 \text { inhibitors vs metformin), favor } \\
\text { metformin }\end{array}$ & $0.28(0.17,0.40)$ & Wu et $\mathrm{al}^{51}$ \\
\hline \multicolumn{3}{|l|}{ inhibitors } \\
\hline \multicolumn{3}{|l|}{ Adverse effects } \\
\hline \multicolumn{3}{|l|}{ Risk of severe hypoglycemia (\%) } \\
\hline SFU & 2.44 & BCRH database \\
\hline DPP-4 inhibitors & $0.55(0.32,4.87)$ & Calculation $^{d}$ \\
\hline Metformin & $0.55(0.32,4.87)$ & Assumption ${ }^{\mathrm{e}}$ \\
\hline \multicolumn{3}{|l|}{ Risk of symptomatic } \\
\hline \multicolumn{3}{|l|}{ hypoglycemia (\%) } \\
\hline SFU & 19.36 & RECAP-DM study ${ }^{61}$ \\
\hline DPP-4 inhibitors & $4.14(2.15,7.99)$ & Calculation $^{f}$ \\
\hline Metformin & $9.41(5.75,15.33)$ & Calculation ${ }^{g}$ \\
\hline Risk ratio of severe & $0.225(0.03,1.99)$ & Rosenstock et $\mathrm{al}^{46}$ \\
\hline \multicolumn{3}{|l|}{ hypoglycemia (DPP-4 inhibitors vs SFU) } \\
\hline Risk ratio of severe & $0.25(0.03,2.19)$ & Pooled analysis ${ }^{\mathrm{h}}$ \\
\hline \multicolumn{3}{|l|}{ hypoglycemia (DPP-4 inhibitors vs metformin) } \\
\hline Risk ratio of symptomatic hypoglycemia (DPP-4 inhibitors vs SFU) & $0.214(0.11,0.4 I)$ & Rosenstock et $\mathrm{al}^{46}$ \\
\hline Risk ratio of symptomatic hypoglycemia (DPP-4 inhibitors vs metformin) & $0.44(0.27,0.72)$ & Wu et $\mathrm{al}^{51}$ \\
\hline
\end{tabular}

Notes: ${ }^{\mathrm{a}} \mathrm{HbA}$, reduction from baseline of DPP-4 inhibitors $=-0.92(-1.20+0.28)$. Upper $95 \% \mathrm{Cl}=-1.03(-1.2+0.17)$ and lower $95 \% \mathrm{Cl}=-0.8(-1.2+0.4)$. ${ }^{\mathrm{b}} \mathrm{Estimate}$ the efficacy of metformin from the pooled analysis of seven studies ${ }^{40,44-49}$ included in the meta-analysis by $\mathrm{Wu}$ et al. ${ }^{51} \mathrm{cHbA}_{\mathrm{Ic}}$ reduction from baseline of $\mathrm{SFU}=-0.83(-0.92+0.09)$. $\mathrm{UPP}_{\mathrm{PP}}$ $95 \% \mathrm{Cl}$ assumed to be $=0(-0.92+\infty)$, lower $95 \% \mathrm{Cl}=-0.98(-0.92-0.06)$. ${ }^{\mathrm{d}}$ Risk of severe hypoglycemia of DPP- 4 inhibitors $=0.55 \%(2.44 \% \times 0.225)$. ${ }^{\mathrm{R}} \mathrm{Risk}$ of severe hypoglycemia

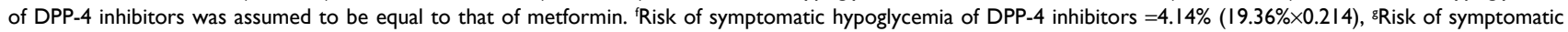
hypoglycemia of metformin $=9.41 \%(4.14 \% / 0.44)$. " $E$ stimate risk ratio of severe hypoglycemia from the pooled analysis of two studies ${ }^{52,55}$ included in the meta-analysis by Wu et al. ${ }^{51}$

Abbreviations: BCRH, Buddhachinaraj Regional Hospital; DPP-4, dipeptidyl peptidase-4; SFU, sulfonylurea. 
studies, ${ }^{52,55}$ for which the RR was estimated. The calculation details are shown in Table 3.

\section{Sensitivity analyses}

To determine the robustness of the findings, we undertook a probabilistic sensitivity analysis and presented the relationship between the probability of favoring DPP-4 inhibitors and the value of the willingness to pay for an additional unit of quality-adjusted life year (QALY) as a cost-effectiveness acceptability curve. The current acceptable Thai ceiling threshold of THB160,000/QALY (US\$4,854.37/QALY) was recommended by the subcommittee for the development of the universal health coverage benefit package and service delivery in Thailand. ${ }^{58} \mathrm{~A}$ series of one-way sensitivity analyses were also performed to determine the effect of $\mathrm{HbA}_{1 \mathrm{c}}$ change, risk of hypoglycemia, drug cost, and discount rate. The results were displayed as a Tornado diagram.

\section{Results}

\section{Base-case analysis}

In the base-case scenario, all three DPP-4 inhibitors incurred higher costs and yielded fewer QALYs (5.965 QALYs vs 5.986 QALYs). In other words, all DPP-4 inhibitors were dominated, making metformin monotherapy a cost-saving treatment in elderly T2DM patients in Thai context (Table 4).

All three DPP-4 inhibitors were more effective (equal 0.031 higher QALYs) but more costly than SFU. Saxagliptin yielded the lowest incremental cost per QALY, followed by vildagliptin and sitagliptin (THB3,632,604/ QALY or US\$110,212.50/QALY, THB4,335,273/QALY or US\$131,531.34/QALY, and THB4,530,556/QALY or US\$137,456.19/QALY, respectively). With the current Thai threshold of THB160,000/QALY (US\$4,854.37/QALY), DPP-4 inhibitors were not cost-effective compared to SFU for treating elderly T2DM patients in the Thai context (Table 4).

\section{Sensitivity analyses}

As vildagliptin and sitagliptin were dominated by saxagliptin, the results of one-way sensitivity analysis, therefore, were displayed on saxagliptin compared to SFU. The change in $\mathrm{HbA}_{1 \mathrm{c}}$ from the baseline of DPP-4 inhibitors, discount rate, risk of severe hypoglycemia, and cost of saxagliptin had some effect on the incremental cost-effectiveness ratio (ICER) (Figure 1). The greater the effect of DPP-4 inhibitors on the reduction of $\mathrm{HbA}_{1 \mathrm{c}}$ from baseline, the lower ICER (Figure 1). Based on the cost-effectiveness

Table 4 Results of DPP-4 inhibitor monotherapy versus metformin monotherapy or SFU monotherapy in base-case analysis

\begin{tabular}{|c|c|c|c|c|c|}
\hline Treatment & $\begin{array}{l}\text { Total cost, } \\
\text { THB (US\$) }\end{array}$ & $\begin{array}{l}\text { Quality- } \\
\text { adjusted } \\
\text { life year }\end{array}$ & $\begin{array}{l}\text { Incremental } \\
\text { costs, THB } \\
\text { (US\$) }\end{array}$ & $\begin{array}{l}\text { Incremental } \\
\text { effectiveness } \\
\text { (QALYs } \\
\text { gained) }\end{array}$ & $\begin{array}{l}\text { Incremental } \\
\text { cost-effectiveness } \\
\text { ratio, THB/QALY } \\
\text { (US\$/QALY) }\end{array}$ \\
\hline \multicolumn{6}{|c|}{ DPP-4 inhibitor vs metformin } \\
\hline \multicolumn{6}{|c|}{ Saxagliptin vs metformin } \\
\hline Saxagliptin & $406,876(12,344.54)$ & 5.965 & Higher cost & Lower QALY & Dominated \\
\hline Metformin & $283,222(8,592.90)$ & 5.986 & & & \\
\hline \multicolumn{6}{|c|}{ Sitagliptin vs metformin } \\
\hline Sitagliptin & $434,982(13,197.27)$ & 5.965 & Higher cost & Lower QALY & Dominated \\
\hline Metformin & $283,222(8,592.90)$ & 5.986 & & & \\
\hline \multicolumn{6}{|c|}{ Vildagliptin vs metformin } \\
\hline Vildagliptin & $428,869(|3,0| 1.80)$ & 5.965 & Higher cost & Lower QALY & Dominated \\
\hline Metformin & $283,222(8,592.90)$ & 5.986 & & & \\
\hline \multicolumn{6}{|c|}{ DPP-4 inhibitor vs SFU } \\
\hline \multicolumn{6}{|c|}{ Saxagliptin vs SFU } \\
\hline Saxagliptin & $406,876(12,344.54)$ & 5.965 & II3,70| (3,449.67) & 0.031 & $\begin{array}{l}3,632,604 \\
(110,212.50)\end{array}$ \\
\hline SFU & $293,175(8,894.87)$ & 5.933 & & & \\
\hline \multicolumn{6}{|c|}{ Sitagliptin vs SFU } \\
\hline Sitagliptin & $434,982(13,197.27)$ & 5.965 & $|4|, 806(4,302.37)$ & 0.031 & $4,530,556$ \\
\hline SFU & $293,175(8,894.87)$ & 5.933 & & & $(137,456.19)$ \\
\hline \multicolumn{6}{|c|}{ Vildagliptin vs SFU } \\
\hline Vildagliptin & $428,869(13,011.80)$ & 5.965 & I35,694 (4,I I6.93) & 0.031 & $4,335,273$ \\
\hline SFU & $293,175(8,894.87)$ & 5.933 & & & $(|3|, 53 \mid .34)$ \\
\hline
\end{tabular}

Abbreviations: DPP-4, dipeptidyl peptidase-4; QALY, quality-adjusted life year; SFU, sulfonylurea; THB, Thai Baht. 


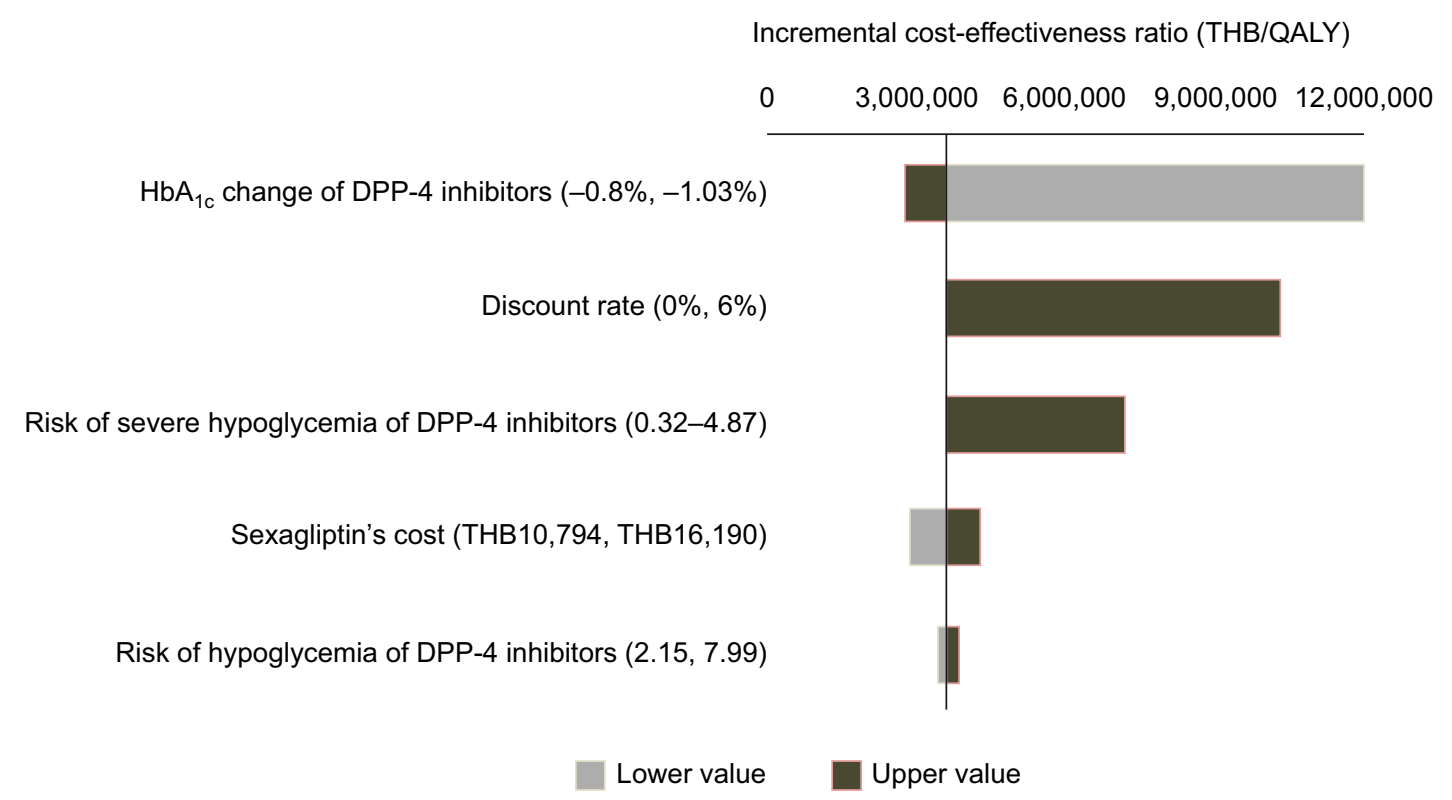

Figure I Tornado diagram of saxagliptin vs sulfonylurea in elderly T2DM patients.

Abbreviations: DPP-4, dipeptidyl peptidase-4; QALY, quality-adjusted life year; T2DM, type 2 diabetes mellitus; THB, Thai Baht.

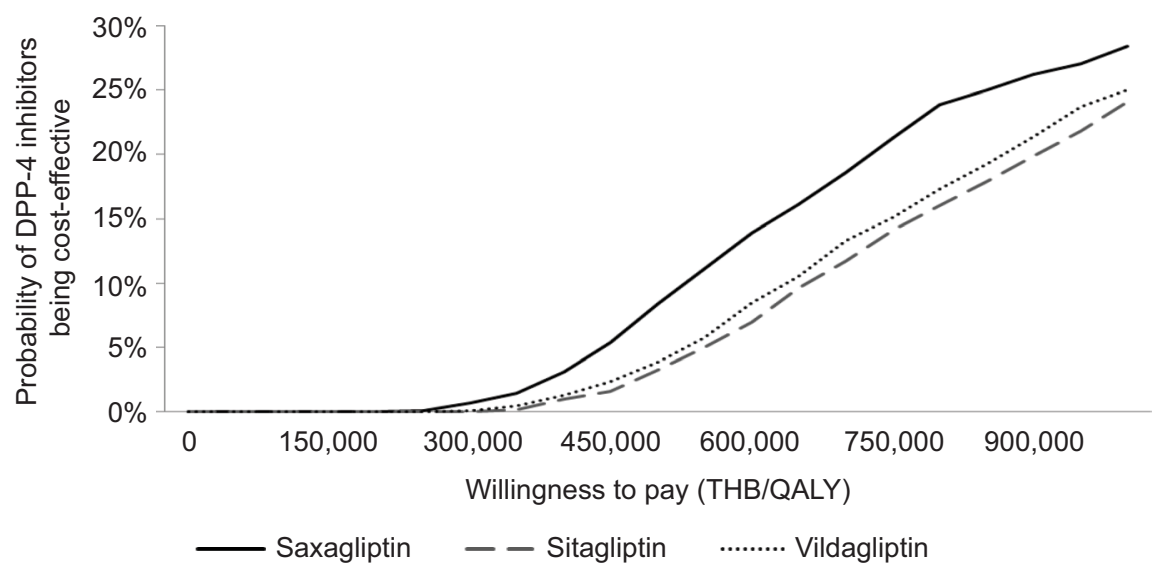

Figure 2 Cost-effectiveness acceptability curve of DPP-4 inhibitors vs sulfonylurea in elderly T2DM patients.

Abbreviations: DPP-4, dipeptidyl peptidase-4; QALY, quality-adjusted life year; T2DM, type 2 diabetes mellitus; THB, Thai Baht.

acceptability curve (Figure 2), all DPP-4 inhibitors were not a cost-effective treatment compared to SFU at the ceiling threshold of 160,000 THB/QALY. Compared to metformin, the probability of DPP-4 inhibitors being cost-effective was even smaller than being compared to SFU.

\section{Discussion}

Elderly patients with diabetes have an increased risk of T2DM-related morbidity and mortality. The treatment goal for elderly T2DM patients is to optimize glycemic control while minimizing the risk of drug-associated adverse events. Thus, this study was conducted to generate economic evidence of DPP-4 inhibitors for T2DM treatment in response to a request by the subcommittee for the development of the National List of Essential Medicine in 2014. The findings of the study were submitted and presented to the subcommittee in 2015 to justify policy decision in terms of the value for money. This cost-effectiveness study followed the Thai national HTA guideline. ${ }^{59}$ Our findings indicated that DPP-4 inhibitor monotherapy was not a cost-effective treatment for elderly T2DM patients in Thailand compared to either SFU monotherapy or metformin monotherapy. Efficacy in $\mathrm{HbA}_{1 \mathrm{c}}$ reduction, risk of severe hypoglycemia, and cost of DPP-4 inhibitors play an important role in the findings of the study.

We are not aware of other studies evaluating the costeffectiveness of DPP-4 inhibitor monotherapy in elderly T2DM patients. Geng et $\mathrm{al}^{60}$ conducted a systematic review of cost-effectiveness of DPP-4 inhibitors for treating T2DM; the eleven included studies assessed DPP-4 inhibitors as an add-on therapy. Of those, seven studies compared DPP-4 
inhibitors and metformin with SFU and metformin. Six studies concluded that DPP-4 inhibitors were cost-effective compared to SFU for treating T2DM patients for whom metformin monotherapy failed to achieve glycemic control.

Our study was strengthened by incorporating input parameters, such as costs, baseline cohort characteristics, and adverse events, from data sources that were reliable and relevant to the Thai context. Similarly, it is important to point out some potential limitations of our study. First, based on our systematic review, we found only one study ${ }^{46}$ that evaluated the efficacy and safety of a DPP-4 inhibitor monotherapy compared to SFU monotherapy in elderly T2DM patients. This study indicated noninferiority in $\mathrm{HbA}_{1 \mathrm{c}}$ reduction but a lower risk of hypoglycemia and no weight gain with the DPP-4 inhibitor monotherapy compared to SFU monotherapy. Only three studies ${ }^{5,47,48}$ compared DPP-4 inhibitor monotherapy with metformin monotherapy in elderly T2DM patients. However, $\mathrm{HbA}_{1 \mathrm{c}}$ reduction after treatment with DPP-4 inhibitors was not significantly different in elderly T2DM patients vs younger T2DM patients. ${ }^{49}$ We addressed this limitation by the pooled analysis of seven studies ${ }^{48,52-57}$ included in the meta-analysis study by $\mathrm{Wu}$ et $\mathrm{al}^{51}$ that compared metformin monotherapy with DPP-4 inhibitor monotherapy in T2DM patients. Second, we tried our best to use resource utilization and cost data from Thailand. Some cost data were not available, such as the cost of an infected ulcer; we assumed them equal to zero. We reanalyzed our base-case analysis, assuming the cost of an infected ulcer similar to an uninfected ulcer. The results showed a slightly lower ICER from THB3,632,604/ QALY (US\$110,212.50/QALY) to THB3,630,697/QALY (US\$110,154.64/QALY) comparing saxagliptin to SFU. Metformin monotherapy was still a dominant treatment compared to DPP-4 inhibitor monotherapy, when assuming equal cost of an infected and uninfected ulcer. The availability of local evidence is another limitation. Even though costs, baseline cohort characteristics, and adverse events were obtained from published studies or hospital databases in Thailand, this study relies on utility values and transition probabilities within the CDM from studies conducted in other countries. Given these limitations, the confirmation of this study's findings may be premature. However, the findings indicate that treating elderly T2DM patients using DPP-4 inhibitor monotherapy in a Thai context may not be cost-effective.

\section{Conclusion}

For treating elderly T2DM patients in Thailand, DPP-4 inhibitor monotherapy is not a cost-effective treatment compared to metformin monotherapy. In addition, DPP-4 inhibitor monotherapy is not a cost-effective treatment compared to SFU monotherapy at the current Thai threshold of THB160,000/QALY. The high acquisition cost of DPP-4 inhibitors is one of the key factors in the findings of this study.

\section{Acknowledgments}

The authors would like to acknowledge the National Drug Selection Working Group in Endocrinology for their valuable advice and comments. In addition, the IMS Team provided training and support for the CDM. This study was supported by grants from the Subcommittees of the National List of Essential Medicine, Thailand.

\section{Disclosure}

The authors report no conflicts of interest in this work.

\section{References}

1. Aekplakorn W, Chariyalertsak S, Kessomboon S, et al. Prevalence and management of diabetes and metabolic risk factors in Thai adults Diabetes Care. 2011;34:1980-1985.

2. Wan EY, Fong DY, Fung CS, Lam CL. Incidence and predictors for cardiovascular disease in Chinese patients with type 2 diabetes mellitus - a population-based retrospective cohort study. J Diabetes Complications. 2015;30(3):444-450.

3. Moran C, Beare R, Phan TG, et al; Alzheimer's Disease Neuroimaging Initiative (ADNI). Type 2 diabetes mellitus and biomarkers of neurodegeneration. Neurology. 2015;85(13):1123-1130.

4. Du YF, Ou HY, Beverly EA, Chiu CJ. Achieving glycemic control in elderly patients with type 2 diabetes: a critical comparison of current options. Clin Interv Aging. 2014;9:1963-1980.

5. Schweizer A, Dejager S, Foley JE, Shao Q, Kothny W. Clinical experience with vildagliptin in the management of type 2 diabetes in a patient population $\geq 75$ years: a pooled analysis from a database of clinical trials Diabetes Obes Metab. 2011;13(1):55-64.

6. Rosenstock J. Management of type 2 diabetes in the elderly. Special considerations. Drugs Aging. 2001;18:31-44.

7. Zhao Y, Kachroo S, Kawabata H, et al. Association between hypoglycemia and fall-related fractures and health care utilization in older veterans with type 2 diabetes. Endocr Pract. 2016;22(2):196-204.

8. Chow JY, Nie JX, Tracy CS, Wang L, Upshur RE. Comorbidity in very old adults with type 2 diabetes mellitus. $J$ Am Geriatr Soc. 2013;61(6):1028-1029.

9. Alonso-Moran E, Orueta JF, Esteban JI, et al. Multimorbidity in people with type 2 diabetes in the Basque Country (Spain): prevalence, comorbidity clusters and comparison with other chronic patients. Eur J Intern Med. 2015;26(3):197-202.

10. Thomas MC, Cooper ME, Zimmet P. Changing epideiology of type 2 diabetes mellitus and associated chronic kidney disease. Nat Rev Nephrol. 2016;12(2):73-81.

11. Thomas MC, Weekes AJ, Broadley OJ, Cooper ME, Mathew TH. The burden of chronic kidney disease in Australian patients with type 2 diabetes (the NEFRON study). Med J Aust. 2006;185(3):140-144.

12. Prasannakumar M, Rajput R, Seshadri K, et al. An observational, crosssectional study to assess the prevalence of chronic kidney disease in type 2 diabetes patients in India (START -India). Indian J Endocrinol Metab. 2015;19(4):520-523.

13. Metsarinne K, Broijersen A, Kantola I, et al; STages of NEphropathy inType 2 Diabetes Study Investigators. High prevalence of chronic kidney disease in Finnish patients with type 2 diabetes treated in primary care. Prim Care Diabetes. 2015;9(1):31-38. 
14. Low SK, Sum CF, Yeoh LY, et al. Prevalence of chronic kidney disease in adults with type 2 diabetes mellitus. Ann Acad Med Singapore. 2015;44(5):164-171.

15. Bailey RA, Wang Y, Zhu V, Rupnow MF. Chronic kidney disease in US adults with type 2 diabetes: an updated national estimate of prevalence based on kidney disease: improving global outcomes (KDIGO) staging. BMC Res Notes. 2014;7:415.

16. Moghissi E. Management of type 2 diabetes mellitus in older patients: current and emerging treatment options. Diabetes Ther. 2013;4(2):239-256.

17. Scheen AJ. A review of gliptins in 2011. Expert Opin Pharmacother. 2012;13:81-99.

18. Palmer AJ, Roze S, Valentine WJ, et al. The CORE diabetes model: projecting long-term clinical outcomes, costs and cost-effectiveness of interventions in diabetes mellitus (type 1 and 2) to support clinical and reimbursement decision-making. Curr Med Res Opin. 2004;20(suppl 1):S5-S26.

19. Palmer AJ, Roze S, Valentine WJ, et al. Validation of the CORE diabetes model against epidemiological and clinical studies. Curr Med Res Opin. 2004;20(suppl 1):S27-S40.

20. Permsuwan U, Guntawongwan K, Buddhawongsa P. Handling time in economic evaluation studies. $J$ Med Assoc Thai. 2014;97(suppl 5):S50-S58

21. Ngarmukos C, Bunnag P, Kosachunhanun N, et al. Thailand diabetes registry project: prevalence, characteristics and treatment of patients with diabetic nephropathy. J Med Assoc Thai. 2006;89(suppl 1):S37-S42.

22. Trongsakul S. The prevalence of undiagnosed cognitive impairment and prevalence of undiagnosed depressive mood in over 60's with type 2 diabetes in a Thai community: a cross-sectional study [dissertation]. Norwich: Faculty of Medicine and Health Sciences, University of East Anglia; 2013.

23. Porapakkham Y, Plattara-Archachai J. Elderly health problems 2004. $J$ Health Syst Res. 2007;1(2):98-115.

24. Thamarangsi T. The Situation of Alcohol Beaverage Consumption and Impact in Thailand 2013. Center for Alcohol Studies, International Health Policy Program, Ministry of Public Health; 2013.

25. Thaneerat $T$, Tangwongchai S. Prevalence of depression, hemoglobin A1c level, and associated factors in outpatients with type 2 diabetes. Asian Biomed (Res Rev News). 2009;3:383-390.

26. The Endocrine Society of Thailand. Diabetes Registry Project 2003. Health Systems Research Institute; 2004.

27. Nitiyanant W, Chetthakul T, Sang-A-kad P, Therakiatkumjorn C, Kunsuikmengrai $\mathrm{K}$, Yeo JP. A survey study on diabetes management and complication status in primary care setting in Thailand. $J$ Med Assoc Thai. 2007;90(1):65-71.

28. Supapluksakul S, Ruamviboonsuk P, Chaowakul W. The prevalence of diabetic retinopathy in Trang province determined by retinal photography and comprehensive eye examination. J Med Assoc Thai. 2008;91(5):716-722.

29. World Health Organization [webpage on the Internet]. Life tables by country: Thailand; 2014. Available from: http://apps.who.int/gho/ data/?theme $=$ main\&vid=61640. Accessed October 15, 2014.

30. Clarke P, Gray A, Holman R. Estimating utility values for health states of type 2 diabetic patients using the EQ-5D (UKPDS 62). Med Decis Making. 2002;22(4):340-349.

31. Tengs TO, Wallace A. One thousand health-related quality-of-life estimates. Med Care. 2000;38(6):583-637.

32. Australian Institute of Health and Welfare. The Burden of Disease and Injury in Australia. 2003.

33. Carrington AL, Mawdsley SK, Morley M, Kincey J, Boulton AJ. Psychological status of diabetic people with or without lower limb disability. Diabetes Res Clin Pract. 1996;32(1-2):19-25.

34. National Institute for Clinical Excellence. Guidance on the Use of Long-Acting Insulin Analogues for the Treatment of Diabetes - Insulin Glargine. 2002.

35. Tanvejsilp P, Ngorsuraches S. Defining the scope of health technology assessment and types of health economic evaluation. J Med Assoc Thai. 2014;97(suppl 5):S10-S16.
36. Maharaj Nakorn Chiang Mai Hospital. Pharmacy and Healthcare Service Fees. Chiang Mai: Maharaj Nakorn Chiang Mai Hospital; 2014.

37. Pornpinatepong S. Cost-effectiveness analysis of diabetic retinopathy screening in type2 diabetes mellitus, Master Thesis, Bangkok, Mahidol University, 2005.

38. Riewpaiboon A. Standard Cost Lists for Health Technology Assessment: Health Intervention and Technology Assessment Program (HITAP). Nonthaburi: HITAP; 2011.

39. National Health Security Office. Schedule of Health Benefits and Fees. Bangkok: National Health Security Office; 2014.

40. Teerawattananon Y, Mugford M, Tangcharoensathien V. Economic evaluation of palliative management versus peritoneal dialysis and hemodialysis for end-stage renal disease: evidence for coverage decisions in Thailand. Value Health. 2007;10(1):61-72.

41. King Chulalongkorn Memorial Hospital. Pharmacy and Healthcare Service Fees. Bangkok: King Chulalongkorn Memorial Hospital; 2014.

42. Bureau of Trade and Economics Indices, Ministry of Commerce [webpage on the Internet]. CPI 2014. Available from: www.price.moc.go.th/ price/cpi/index_new_e.asp. Accessed October 12, 2014.

43. Bank of Thailand [webpage on the Internet]. Foreign exchange rates 2015. Available from: https://www.bot.or.th/english/statistics/financialmarkets/exchangerate/_layouts/application/exchangerate/ExchangeRate.aspx. Accessed February 11, 2016.

44. Drug and Medical Supply Information Center [homepage on the Internet]. 2015. Available from: http://dmsic.moph.go.th. Accessed April 15, 2016.

45. Riewpaiboon A. Measurement of costs for health economic evaluation. J Med Assoc Thai. 2014;97(suppl 5):S17-S26.

46. Rosenstock J, Wilson C, Fleck WP. Alogliptin versus glipizide monotherapy in elderly type 2 diabetes mellitus patients with mild hyperglycaemia: a prospective, double-blind, randomized, 1-year study. Diabetes Obes Metab. 2013;15(10):906-914.

47. Pratley RE, Rosenstock J, Pi-Sunyeer FX, et al. Management of type 2 diabetes in treatment-naive elderly patients. Diabetes Care. 2007;30:3017-3022.

48. Schweizer A, Dejager S, Bosi E. Comparison of vildagliptin and metformin monotherapy in elderly patients with type 2 diabetes: a 24-week, double-blind, placebo-controlled study. Diabetes Obes Metab. 2009;11:804-812.

49. Schwartz SL. Treatment of elderly patients with type 2 diabetes mellitus: a systematic review of the benefits and risks of dipeptidyl peptidase-4 inhibitors. Am J Geriatr Pharmacother. 2010;8(5): 405-418.

50. Karagiannis T, Paschos P, Paletas K, Matthews DR, Tsapas A. Dipeptidyl peptidase- 4 inhibitors for treatment of type 2 diabetes mellitus in the clinical setting: systematic review and meta-analysis. $B M J$. 2012;344:e1369.

51. Wu D, Li L, Liu C. Efficacy and safety of dipeptidyl peptidase-4 inhibitors and metformin as initial combination therapy and as monotherapy in patients with type 2 diabetes mellitus: a meta-analysis. Diabetes Obes Metab. 2014;16(1):30-37.

52. Pfutzner A, Paz-Pacheco E, Allen E, Frederich R, Chen R; CV181039 Investigators. Initial combination therapy with saxagliptin and metformin provides sustained glycaemic control and is well tolerated for up to 76 weeks. Diabetes Obes Metab. 2011;13(6):567-576.

53. Aschner P, Katzeff HL, Guo H, et al; Sitagliptin Study 049 Group. Efficacy and safety of monotherapy of sitagliptin compared with metformin in patients with type 2 diabetes. Diabetes Obes Metab. 2010;12(3): 252-261.

54. Williams-Herman D, Johnson J, Teng R, et al. Efficacy and safety of sitagliptin and metformin as initial combination therapy and as monotherapy over 2 years in patients with type 2 diabetes. Diabetes Obes Metab. 2010;12(5):442-451.

55. Bosi E, Dotta F, Jia Y. Vildagliptin plus metformin combination therapy provides superior glycaemic control to individual monotherapy in treatment naive patients with type 2 diabetes mellitus. Diabetes Obes Metab. 2009;11:506-515. 
56. Schweizer A, Couturier A, Foley JE. Comparison between vildagliptin and metformin to sustain reductions in $\mathrm{HbA}(1 \mathrm{C})$ over 1 year in drugnaive patients with type 2 diabetes. Diabet Med. 2007;24:955-961.

57. Haak T, Meinicke T, Jones R, Weber S, von Eynatten M, Woerle HJ. Initial combination of linagliptin and metformin improves glycaemic control in type 2 diabetes: a randomized double-blind, placebo-controlled study. Diabet Obes Metab. 2012;14(6):565-574.

58. Teerawattananon Y, Tritasavit N, Suchonwanich N, Kingkaew P. The use of economic evaluation for guiding the pharmaceutical reimbursement list in Thailand. Z Evid Fortbild Qual Gesundhwes. 2014;108(7):397-404.
59. Health Technology Assessment Working Team. The Guidelines for Health Technology Assessment of Thailand. 2nd ed. Nonthaburi: Watcharin PP; 2014

60. Geng J, Yu H, Mao Y, Zhang P, Chen Y. Cost-effectiveness of dipeptidyl peptidase- 4 inhibitors for type 2 diabetes. Pharmacoeconomics. 2015;33:581-597.

61. Chan SP, Ji LN, Nitiyanant W, Baik SH, Sheu WH. Hypoglycemic symptoms in patients with type 2 diabetes in Asia-Pacific: real-life effectiveness and care patterns of diabetes management: the RECAPDM study. Diabetes Res Clin Pract. 2010;89:e30-e32.
ClinicoEconomics and Outcomes Research

\section{Publish your work in this journal}

ClinicoEconomics and Outcomes Research is an international, peerreviewed open-access journal focusing on health technology assessment, pharmacoeconomics and outcomes research in the areas of diagnosis, medical devices, and clinical, surgical and pharmacological intervention. The economic impact of health policy and health systems
Submit your manuscript here: https://www.dovepress.com/clinicoeconomics-and-outcomes-research-journal

organization also constitute important areas of coverage. The manuscript management system is completely online and includes a very quick and fair peer-review system, which is all easy to use. Visit http://www.dovepress.com/testimonials.php to read real quotes from published authors. 